\title{
EL CUIDADO ESPIRITUAL Y FÍSICO: PRIMERAS ATENCIONES A LA INFANCIA EN LA ESPAÑA DEL SIGLO XVIII
}

\author{
Spiritual and Physical Care: First Child Care in the XVIII's Century Spain
}

\author{
Elena Martínez AlcÁZAR \\ Universidad de Murcia \\ emalcazar@um.es
}

Fecha de recepción: $31-\mathrm{I}-2013$

Fecha de aceptación: 07-II-2013

\begin{abstract}
Resumen: Se pretende abordar cuáles eran los cuidados que recibían los niños durante sus primeros años de vida en la España del setecientos. Para ello se han analizado diversas obras literarias, tratados, sermones, artículos de la prensa periódica y una serie de testamentos e inventarios de bienes expedidos en el entorno murciano y madrileño. A lo largo del siglo XVIII, el tema de la infancia adquirió más relevancia que en épocas anteriores. La ideología ilustrada proclamaba que había de mejorarse el tratamiento hacia este estado de la vida como premisa para la obtención de individuos sanos, vigorosos y activos. Cuestión que hubo de convivir con una serie de costumbres, notablemente marcadas por la religión y la superstición, en un país que se debatía entre lo tradicional y lo moderno.
\end{abstract}

Palabras clave: Infancia, Siglo XVIII, bautismo, lactancia, vestuario, amuletos.

Авstract: It is intended here to approach which were the cares children received during their early years of live in the Eighteenth century. In order to do this several literary works, treatises, sermons, newspaper articles and a regular series of wills and inventories of goods dispatched in the environment Murcia and Madrid have been analyzed. Throughout the eighteenth century, the issue of childhood acquired more relevance than in the past. The Enlightenment ideology proclaimed that the treatment to that stage of life had to be improved as a prerequisite for obtaining healthy, vigorous and active individuals. Issue that had to live with a set of customs, notably marked by 
religion and superstition, in a country that was struggling between the traditional and the modern.

Keywords: Children, eighteenth century, baptism, breastfeeding, clothing, amulets.

\section{INTRODUCCIÓN}

En el Antiguo Régimen las condiciones sanitarias y la deficiente labor médica hacían que los alumbramientos estuvieran plagados de peligros que podían atentar contra la vida del infante y de la madre. Muchos morían en su intento por descubrir el mundo y otros tantos perdían la vida a los pocos días de nacer. Numerosos rituales y objetos profilácticos acompañaban a la madre a lo largo de la gestación y durante el parto y, de igual forma, muchos eran los amuletos con los que se cubrían a los nińos durante sus primeros años de vida, puesto que eran los seres más indefensos y más propensos a las enfermedades y los padecimientos de maleficios como el mal de ojo.

La fuerte religiosidad de la época hacía necesario que las mujeres y los recién nacidos fueran bautizados, las primeras, si no lo estaban, pocos días antes de dar a luz y los segundos dos o tres días tras el alumbramiento o de inmediato si su vida corría peligro. Por otro lado, fue el siglo XVIII el momento en que se establecieron las características y cualidades propias de la infancia, fruto del mayor interés hacia este ciclo de la vida, que había ido fraguándose en el Seiscientos. Con anterioridad, los niños no eran tan valorados en su primera infancia como lo hicieron en esta época, puesto que sólo adquirían importancia dentro del núcleo familiar cuando ya podían ayudar, con su trabajo y esfuerzo, a su sostenimiento. Sin embargo, el Setecientos generó todo un entramado de tratados y disposiciones en torno a su cuidado, educación y salud ${ }^{1}$, descubriendo al mismo tiempo un sentimiento protector y benevolente hacia la indefensión de su estado. Fundamentales en este sentido fueron las aportaciones de Rousseau, quien, defendiendo el mito del buen salvaje, creía que el nińo era bueno por naturaleza y que la sociedad era la que podía o no corromperlo, además de puntualizar que la educación que recibiera tenía que ser acorde con su edad, puesto que, en cada fase de desarrollo, el nińo experimentaba diferentes etapas en su evolución física, moral e intelectual. Dando libertad al desarrollo de la parte natural o inherente a la condición humana desde la infancia, Rousseau

\footnotetext{
A medida que transcurrió la Edad Moderna fue generándose una nueva concepción del cuerpo propio. Se recomendaba preservarlo de cualquier daño, antes que curar algún padecimiento físico. Por tanto, como indicó Gélis, en el siglo XVIII «el cuerpo gana autonomía, se individualiza». Ya no se ofrecían únicamente sus cualidades al servicio de la colectividad, ahora se cuidaba y mantenía por la simple intención de gozar de buena salud y, por ende, de tener una buena calidad de vida. Aún en el convencimiento de la caducidad de lo corporal, la nueva mentalidad de finales del Antiguo Régimen permitía extrapolar su preservación y cuidado al de los descendientes. GÉLIS, J. «La individualización del niño» en ARIÈS, P. y DUBY, G. Historia de la vida privada. Del Renacimiento a la Ilustración, t. III, Madrid, Taurus, 1989, p. 317.
} 
apuntó en el Emilio que se potenciaría la bondad intrínseca del hombre, lo que le permitiría vivir en una sociedad corrompida sin mutar sus propios principios ${ }^{2}$.

En el campo de la literatura los temas infantiles no habían sido tan protagonistas de los relatos hasta llegar al siglo tratado. A partir de este momento, numerosos autores introdujeron a los niños en las tramas de sus novelas, haciéndoles partícipes en diversas escenas públicas y privadas, relacionándolos con hermanos y amigos e indagando en los problemas y situaciones diarias que afrontaban. De igual forma, en diversos países europeos empezaron a aparecer fábulas destinadas principalmente a los niños de las escuelas con objeto de contribuir a la formación de su carácter, disciplina y sociabilidad. A finales del Setecientos comenzaron a distribuirse ciertas publicaciones periódicas dedicadas únicamente a la infancia donde se establecían consejos pedagógicos y didácticos para ayudar a los padres en la educación de sus hijos. En los inicios del género en España se halla la Gaceta de los Niños (1798), inspirada en la publicación francesa de Jouffret llamada el Correo de los Niños?.

En el arte los niños aparecían principalmente en las escenas familiares, donde compartían protagonismo con sus padres, criadas o abuelos ${ }^{4}$. A medida que las teorías ilustradas fueron definiendo su programa de defensa a ultranza de la familia como institución de capital importancia para la individualidad y la sociedad, los lazos amorosos, tiernos y delicados con los hijos se multiplicaron tanto en las representaciones de las clases bajas como en las de las altas esferas. Pero también se les reflejaba jugando o entreteniéndose con otros infantes en un intento por dulcificar la consideración hacia su estado.

2 ROUSSEAU, J. J. Emilio, Buenos Aires, Tecnibook, 2011, pp. 3-4. El director de cine François Truffaut llevó el tema del buen salvaje a la gran pantalla con El pequeño salvaje (1969).

3 BRAVO VILLASANTE, C. "El niño en la literatura española», Boletín del Museo e Instituto Camón Aznar, no 19, 1985, p. 12.

4 Hasta llegar a este tipo de representaciones, cabe mencionar, a grandes rasgos, cómo se fue fraguando el interés hacia el tema de la infancia, género que comenzó a desarrollarse principalmente en el arte religioso. En el siglo XI los parvuli se representaban sin rasgos físicos que los identificaran como niños, únicamente se los tallaba en tamaño reducido. Fue a partir de la segunda mitad del siglo XII cuando comenzaron a dulcificarse las escenas en las que Jesús niño aparecía con la Virgen. Eran reproducciones en las que, paulatinamente, el Hijo de Dios mostraba actitudes cariñosas con su madre o jugaba con animalillos y diversos objetos. Sin embargo, este nuevo modelo tardó en contaminar a las imágenes laicas, que no comenzaron a retratar fielmente a los infantes hasta finales del siglo XV. Muy importantes fueron también las representaciones de los niños fallecidos, pues implicó una forma novedosa en cuanto a la afectividad hacia los hijos. Aún siendo natural que las muertes en la primera edad sacudieran a multitud de familias, ya se atisbaba un afecto y apego por aquella alma que había dejado su huella, aunque fugaz, en este mundo. Se estaba tomando conciencia de su inmortalidad. A lo largo del Seiscientos aumentó el número de retratos en los que el niño era protagonista del núcleo familiar y en el siglo XVIII ciertos artistas cultivaron una temática específica dedicada a la infancia, donde los párvulos eran representados jugando, aprendiendo a leer o recitando música, entre otros. ARIÈS, P. El niño y la vida familiar en el Antiguo Régimen, Madrid, Taurus, 1988. Véase también RAMÍREZ ALVARADO, M. «La imagen de la infancia: aspectos iconográficos», Comunicar, no 24, 2005, pp. 129-132. 
En las postrimerías del Antiguo Régimen empezaron a especificarse ciertas condiciones para favorecer los cuidados físicos de los párvulos y, de igual forma, fue el momento en que se estimó propicio alejar al niño de la calle, de la vecindad y del oficio, para depender, durante los primeros años de existencia, del núcleo familiar ${ }^{5}$. Los padres debían estar más atentos de sus vástagos durante sus primeros ańos de vida. El fortalecimiento del patriarcado y los lazos y afectos familiares que se produjeron desde finales del siglo XVII, donde los conceptos de intimidad y privacidad cobraron especial protagonismo $^{6}$, hicieron que el niño recibiera un nuevo tratamiento, coherente con su insuficiente desarrollo físico y moral.

Los escritos de la época reseñaban el importante papel de los padres como educadores de sus hijos, si bien, hay que tener en cuenta que en ningún momento se olvidó la doctrina religiosa como sustento fundamental del proceso educativo. Se atenuaron algunos pensamientos tradicionales eclesiásticos como la predisposición cristiana a considerar al recién nacido más proclive al mal que al bien -según habían establecido los Padres de la Iglesia- aduciendo que era consecuencia del pecado original y motivo del desorden natural de sus sentimientos y facultades. Sin embargo, aunque en algunos tratados religiosos de la época se incentivaran el cuidado físico, la higiene o la adecuación de las enseńanzas para cada estado de la infancia, no terminaban de desligarse de ciertos prejuicios tradicionales hacia los nińos como su tendencia natural al pecado que había que eliminar con severos castigos y rígidas actitudes ${ }^{7}$.

Las atenciones espirituales de los hijos que tanto proclamaban los religiosos siguieron manteniendo un protagonismo relevante a finales del Antiguo Régimen, sin embargo a lo largo del Setecientos otros fundamentos fueron enaltecidos, como el cuidado por el desarrollo físico e intelectual. Los ideales ilustrados de felicidad y prosperidad pública requerían que las nuevas generaciones fueran partícipes de los adelantos

5 VARELA FERNÁNDEZ, J. «La Educación Ilustrada o cómo fabricar sujetos dóciles y útiles», Revista de Educación, no extraordinario 1, 1988, p. 250. Los nińos en la calle -jugando entre ellos o buscando y robando comida- fue uno de los géneros que en el siglo XVII había tratado Murillo en pinturas como Niños jugando a los dados, Niños comiendo melón o Niños comiendo pastel, cuadros en los que el artista puso de manifiesto la picaresca a la que tenían que recurrir unos infantes asolados por las miserias de la Sevilla de la época. A pesar de su pobreza, reflejada especialmente en sus ropajes harapientos y ausencia de calzado, se trata de nińos que nunca pierden la sonrisa. Según apuntó Moreno Mendoza, «los niños de Murillo son para el maestro objetivo prioritario de caridad en un mundo de adultos injusto y egoísta». MORENO MENDOZA, A. "Murillo, la "santificación" de la pobreza», Pandora, no 4, 2004, p. 33.

6 LIGUORI GUELFI, R. «Radiografía de la familia y la infancia: antiguos y nuevos saberes», Revista de psicoanálisis, psicoterapia y salud mental, v. 1 no 2, 2008 http://psi.usal.es/rppsm/pdfn2/ radiografiadelafamiliaylainfancia.pdf [Consulta: 20 de junio de 2011].

7 Recogido por CAVA LÓPEZ, M. G. «La infancia en el siglo XVIII español: concepto, realidad e imagen» en XXX Coloquios Históricos de Extremadura, Trujillo, 2002 http://www.chde. org/index.php?option $=$ com_content $\&$ view $=$ article $\& i d=311$ :infancia-siglo-xviii-espanol $\&$ catid=35:2001\&Itemid=52 [Consulta: 23 de noviembre de 2011]. 
de la modernidad. Por tanto, los padres debían esmerarse en criar a sus vástagos como súbditos provechosos para el Estado.

\section{LA INICIACIÓN ESPIRITUAL: EL BAUTISMO}

Inmediatamente al nacimiento, o muy pocos días después, los padres tenían la obligación de bautizar a sus hijos si querían darles la opción a la redención eterna. Era una premisa necesaria para eliminar todo el lastre de fatalidad y pecado que arrastraba consigo la raza humana desde los albores de su creación, el cimiento requerido para iniciar la formación espiritual. Diversos textos teológicos, reeditados en el siglo XVIII, remitían continuamente en sus sermones a la misericordia de Dios, que había tenido a bien redimir a los hombres con este sacramento de todos los males. El niño llegaba al mundo contaminado, pero tenía esta gracia divina para iniciar su proceso de salvación:

Considera, como naciste de pecado original, enemigo de Dios, hijo de ira, y de perdicion, esclavo del demonio, desterrado para siempre de los Cielos, y condenado á penas eternas, y tu alma fea, y abominable con la mancha del Pecado; y que con el agua del Santo Bautismo fue lavada, y limpia de toda esta fealdad, y bañada en la Sangre de Jesu Christo ${ }^{8}$.

De vital importancia para la mentalidad religiosa del momento era aleccionar y advertir a los progenitores sobre la relevancia de dispensarle este don a sus hijos y las consecuencias nefastas que podían experimentar los mismos si no llegaba a realizarse o si se hacía de manera incorrecta. La idea fundamental sobre la que se sustentaban estas lecciones era el convencimiento férreo de la Iglesia de que el infante estaba condenado al Infierno por ley divina al nacer. Por este motivo, necesitaba bautizarse con prontitud. Los que no recibieran el bautismo, es decir, los que murieran en el vientre materno o a los pocos días de nacer y los que quedaran privados del Sacramento, no tendrían la opción de salvarse.

En la línea discursiva de este tema se usaba también el recurso del reflejo físico de la corrupción interior causada por el demonio. La fealdad no sólo revestía el alma, el cuerpo de los niños no bautizados solía ser amorfo, ennegrecido y hasta monstruoso, según contaba el padre Echeverez en sus Pláticas doctrinales ${ }^{9}$. Estas alusiones a la deformidad de los

8 MOLINA, A. de. Exercicios espirituales de las excelencias, provecho, y necesidad de la oración mental, reducidos a la Doctrina, y meditaciones, sacados de los Santos Padres, y Doctores de la Iglesia, Barcelona, Eulalia Piferrer, 1776, pp. 356-357.

9 Recogido por FERNÁNDEZ CORDERO, M. J. Pastoral y apostolado de la palabra en el siglo XVIII: la reforma de la predicación en su dimensión práctica, Tesis doctoral, t. I, Madrid, Universidad Complutense, 1993, p. 458. 
hijos se hacían de una manera totalmente consciente, pues era notorio que las apariencias y todo lo que tuviera relación con el mundo terrenal tenían mayor calado en la sociedad. Ningún padre querría que sus retońos tuvieran ese aspecto. Las verdades teológicas, a menudo difíciles de comprender, se aderezaban con variedad de referencias tangibles para hacerlas más cercanas e impactantes.

Las circunstancias de los nacimientos no se podían prever. De antemano, nadie sabía la urgencia y los requerimientos que necesitaría el niño. Por esta causa el bautismo no siempre se daba de la misma manera ni por las mismas personas. A veces se podía esperar a que llegase el párroco, pero otras no. Los manuales de ejercicios espirituales daban instrucciones sobre quién debía hacerlo, cómo se hacía, cuál era el ritual e, incluso, el tipo de agua que se usaba en cada situación. Había dos manera de bautizar, de forma solemne, cuando el sacerdote bautizaba en la iglesia, y de manera privada, en la propia vivienda, cuando la vida del recién nacido corría peligro. A este último caso se le denominaba «bautismo de necesidad» y lo podían administrar hombres y mujeres de la religión que fuese, incluso «judíos, infieles y hereges, con tal que tengan intención de hacer lo que hace la Iglesia católica en la administración de este sacramento ${ }^{10}$ ». Sin embargo, había jerarquías para cada una de las dos formas de bautismo. Cuando se administraba con solemnidad tenían la prerrogativa los obispos y sacerdotes, a quienes pertenecía su administración por derecho propio. En caso de no poder éstos, le seguían los diáconos, aunque sólo podían aplicarlo con permiso de los antecedentes. Para el bautismo de necesidad, como se ha comentado, estaba capacitado el común de las gentes. Sin embargo, había también unas preferencias:

\begin{abstract}
Mas no piensen los fieles que está este oficio tan indiscretamente permitido á todos, que no sea muy decente asentar algún órden de ministros. Porque ni la mujer, si hay hombre, ni el seglar delante del clérigo, ni el clérigo en presencia del Sacerdote se deben arrogar la administración. Aunque las parteras que estan acostumbradas á bautizar no han de ser reprehendidas si alguna vez le dan en presencia de hombre que está menos instruido en hacer este sacramento, sin embargo de que parezca oficio mas propio del hombre que de la mujer ${ }^{11}$.
\end{abstract}

Los mecanismos presentes en el bautismo, es decir, el agua y las palabras que debían pronunciarse mientras se realizaba, eran de vital importancia para que no se diera por nulo. En la Iglesia debía el niño bautizarse con el agua bendita de la pila bautismal, pudiendo pecar el ministro de Cristo que usase otra, aunque estuviera bendecida. En la intimidad del hogar valía cualquier agua natural que se sacase de ríos, cisternas, fuentes

10 Catecismo del Santo Concilio de Trento para los parrocos, ordenado por disposición de San Pio V, t. I, Barcelona, Imprenta de Sierra y Martí, 1833, p. 163.

11 Ibidem, p. 164. 
y pozos, no así las aromatizadas y destiladas. El líquido tenía que rociarse sobre la cabeza «por ser ésta el mas principal de todos los miembros exteriores: en ella se manifiesta el principio de la vida sensitiva, y hasta la mas noble accion, qual es la intelectiva, la executa el alma en la cabeza». Aunque se daba la excepción de echarla en otra parte del cuerpo cuando el nińo viniera de nalgas y tuviera peligro de morir o hubiese fallecido ya en el vientre materno. Las palabras pronunciadas durante el sacramento eran esenciales. Si no se recitaba: «Yo te bautizo en el nombre del Padre, y del Hijo y del Espíritu Santo» en su totalidad y sin añadiduras, la criatura no gozaría de la salvación eterna ${ }^{12}$.

Cabe mencionar que la doctrina teológica a menudo era de difícil comprensión para la plebe. A esto hay que añadir, como indica Fernández Cordero, que los beneficios y efectos del Bautismo no fueron tratados con la misma prodigalidad que su carácter obligatorio para la redención y las terribles consecuencias de no recibirlo ${ }^{13}$. Algunos eclesiásticos fueron conscientes, en parte, de su culpa, admitiendo que los comportamientos errados de la gente de su época se debían a que ignoraban el verdadero contenido espiritual que tenía este sacramento. Éste era un regalo, un don, un privilegio otorgado por Dios a la humanidad para que iniciara su rumbo en la vida sin pecado original, pero no significaba que eximiera de los castigos que se sufrirían en el Purgatorio por las faltas cometidas en este mundo. Debían por tanto acordarse de esta dádiva y hacerse dignos merecedores de ella en su cotidianeidad. La idea básica estribaba en una especie de ajuste de cuentas. Cuentas que, la formación y la práctica religiosa diaria, podían saldar.

\section{LA LACTANCIA Y LOS EXPÓSITOS}

Tras el nacimiento, el papel de la madre era fundamental para un correcto desarrollo físico del niño. Su alimentación debía cuidarse desde el principio y la leche materna se iba constituyendo como la mejor opción para su salud, en detrimento de la labor que ejercían, con asiduidad, las nodrizas o amas de cría ${ }^{14}$. Principalmente recurrían a estas mujeres las clases altas que tenían el dinero necesario para tenerlas a su cargo. A esto se unía una creencia muy extendida en la época sobre la dificultad de que las féminas que daban su leche a sus hijos pudieran quedar encintas. Por otro lado, se tenía la convicción moralista y médica de que las mujeres lactantes no podían tener relaciones sexuales por las terribles consecuencias que tenían para su alma y su cuerpo. Se sacaba así el máximo

12 SALSAS Y TRILLAS, P. De pláticas doctrinales y espirituales sobre los puntos de la doctrina Christiana, apoyado en la sagrada Escritura, Santos Padres y Doctores Católicos, t. IV, Madrid, Imprenta de la viuda e hijo de Marín, 1800, pp. 126-129.

13 FERNÁNDEZ CORDERO, M. J. op.cit., p. 464.

14 No era una cuestión novedosa, pues en etapas anteriores moralistas y religiosos debatieron sobre si era adecuado o no recurrir a las amas de cría. Véase TENORIO GÓMEZ, P. Realidad social y situación femenina en el Madrid del siglo XVII, Tesis doctoral, Madrid, Universidad Complutense, 1991, pp. 349-362. 
partido a la fertilidad femenina, pues, al no ofrecer su alimento a los hijos, continuaban sus relaciones sexuales sin riegos ${ }^{15}$.

De igual forma, negarse a amamantarlos suponía la ventaja de poder seguir realizando las actividades cotidianas, evitando también la pérdida de belleza:

Pocas veces por insuficiencia láctea de la madre, las más por no quedar prisionera de los bracines de la criatura y tener que desertar de la vida social, y también por miedo a un ajamiento prematuro («el parir, embellece, y el criar, envejece»), era hasta de buen tono en las clases pudientes ponerle ama al recién nacido ${ }^{16}$.

Se consideraba un signo de distinción social ${ }^{17}$, pues incluso la realeza recurría a las amas de cría. Si las clases inferiores se veían en la necesidad de contratarlas era por la necesidad lógica de continuar con el duro trabajo diario, indispensable para el sustento familiar, aunque, si bien es cierto, esta práctica no era tan característica de los estratos más desfavorecidos por la imposibilidad de hacer frente al estipendio de las nodrizas. Incluso en los casos de necesidad más extrema, en los que no se podían emplear a estas féminas o en los que las madres no disponían de la calidad de leche necesaria por encontrarse debilitadas en exceso, en algunas zonas se recurría a la leche de cabra o burra ${ }^{18}$. Se elegía el mejor animal de la camada y se le doblaban la alimentación y los cuidados, pues algunos habitaban el espacio doméstico para que no tuvieran riesgo de contagio de enfermedades o fueran mordidos por otros animales. En estos casos, el infante mamaba directamente de la cabra hasta que estaba en edad de variar su sustento ${ }^{19}$. Algunos tratados sobre la crianza

15 HERNÁNDEZ GONZÁLEZ, M. Mujer y vida cotidiana en Canarias en el siglo XVIII, Tenerife, Centro de la Cultura popular Canaria, 1998, p. 45.

16 CASAS GASPAR, E. Costumbres españolas de nacimiento, noviazgo, casamiento y muerte, Madrid, Escelicer, 1947, p. 69.

17 Algunos novelistas de la época ponían en boca de ciertas protagonistas frívolas, altaneras y educadas en las nimiedades de las modas este tipo de justificaciones para solicitar los servicios de una nodriza, aunque no se necesitasen. Por ejemplo, si las madres ilustres tenían costumbre de amamantar a sus hijos, los llantos de éstos solicitándolas, molestarían a los invitados de sus tertulias. En el momento que acudían a satisfacerlos, perdían el hilo de las conversaciones de tales reuniones, quedando atrasadas en el discernimiento sobre las modas en boga. También era causa de afeamiento en el talle y una pérdida de ocasión para mostrar ante los demás que se seguían los usos modernos -aunque el hecho de contratar a un ama de cría nada tenía de novedoso-. REJÓN Y LUCAS, D. V. Aventuras de Juan Luis. Historia divertida que puede ser útil, Madrid, Joachin Ibarra, 1781, p. 9. Sobre este autor de origen murciano, padre del Académico y teórico del arte Diego Antonio Rejón de Silva, que al parecer escribió la única novela en la Murcia del Setecientos, véase AMORÓS, A. «Estudio preliminar» en REJÓN Y LUCAS, D. V. Aventuras de Juan Luis, Murcia, Tres Fronteras, 2008 (Facsímil, Madrid, Joaquín Ibarra, 1781), pp. XI-XXII.

18 FERRÁNDEZ OBRADORS, V. Una historia de esperanza. La casa de expósitos de Cartagena. 1720-1950, Murcia, Víctor Ferrández Obradors, 2011, p. 28.

19 JORDÁN MONTES, J. F. y PEÑA ASENSIO, A. de la. «Ritos de tránsito en la Sierra de Yeste y de Nerpio (Provincia de Albacete)» en ÁLVAREZ MUNARRIZ, L., FLORES ARROYUELO, 
de expósitos insertaban láminas con artilugios que se colocaban a los animales para que los recién nacidos mamaran cómodamente ${ }^{20}$.

En un estadio intermedio estaban las mujeres de clase media que contrataban a las nodrizas campesinas para que se llevaran a sus criaturas de las ciudades, ya que diversos estudios a nivel europeo habían demostrado estadísticamente que la tasa de mortandad de los recién nacidos era mayor entre los que vivían en las urbes ${ }^{21}$.

El caso es que el contrato de nodrizas fue una circunstancia muy común, como lo demuestra la cantidad de anuncios de la prensa en los que las familias solicitan los servicios de las amas y viceversa: "Casa de don Pablo de Medina (...) buscan un Ama para criar una Nińa de diez meses»; «Se busca una Ama robusta ${ }^{22}$, Soltera, que no pase su leche de diez meses»; "Ginés Collados Maestro de Sastre en la Calle de Zambrana, busca una Ama para criar un niño de 4 meses en su Casa: ha de ser muger sola, y de buena leche, y se le darán 4 Ducados, comida y ropa limpia todos los meses»; «En la puerta del Sol, casa de Alfonso Martínez Maestro de Sangrador, darán razón de una Nodriza, Muger sola y abonada»; «Nodriza Antonia García de estado casada 24 ańos de edad, y leche de dos meses, busca Cria para fuera de su casa»; «Teresa García de 28 años de edad, y leche fresca, busca cria para su casa»; "Josefa García de 28 años de edad y 10 meses de leche de Niña, busca cria para fuera de su $\operatorname{casa}^{23}$ ".

F. J. y GONZÁLEZ BLANCO, A. (Eds.): Cultura y sociedad en Murcia, Murcia, Universidad de Murcia, 1993, p. 333.

20 Véase GARCÍA, S. Instituciones sobre la crianza física de los niños expósitos, Madrid, Vega y Compañía, 1805.

21 HUFTON, O. «Mujeres, trabajo y familia» en DUBY, G y PERROT, M. (Dirs.): Historia de las mujeres en Occidente. Del Renacimiento a la Edad Moderna, t. III, Madrid, Taurus, 1992, p. 55.

22 El buen estado físico de las nodrizas, aunado a la pureza de costumbres, era condición indispensable para que los padres las contrataran porque se estimaba que el estado de su leche estaba directamente relacionado con su salud física y espiritual. En un artículo del Correo de Murcia, a pesar de defenderse la lactancia materna, se advertía a las mujeres que tuvieran que contar con la ayuda de las amas lo siguiente: "procurar que la Nodriza sea una mujer digna en todo lo posible de desempeñar el titulo de madre, juntando a una salud robusta, un alma pacífica, y unas costumbres irreprehensibles, porque de aquí dependen según ya tengo apuntado, las qualidades físicas y morales del infante; qualidades que la educación puede mejorar, pero que siempre guardan el sello del vicio ó de la virtud, que la leche le comunicó en su infancia». Correo de Murcia, no 117, 10 de mayo de 1794, p. 17. Diversos tratados para la crianza de los recién nacidos hicieron alusión a la forma corporal más idónea de estas mujeres. Por ejemplo, el catedrático de partos y enfermedades Agustín Ginesta pensaba que debía ser morena o castańa, tener los ojos negros, buena dentadura, más o menos la misma edad de la madre, además de ser «robusta, ágil y aseada». GINESTA, A. El conservador de los niños, Madrid, Imprenta Real, 1791, p. 10. Otros añadían a éstas más cualidades físicas como tener un buen aliento, pechos medianos, consistentes y sin durezas, pezones encarnados y elevados y una sudoración que no fuera desagradable. BONELLS, J. Perjuicios que acarrean al género humano y al estado las madres que rehusan criar à sus hijos, y medios para contener el abuso de ponerlos en Ama, Madrid, Miguel Escribano, 1786, p. 89.

23 Diferentes anuncios del Diario de Murcia entre el 28 de febrero y el 8 de mayo de 1792, no 5, 7, $71,118,19,75$ y 59 , respectivamente. 
Aunque ya desde el siglo XVI hubo diversas obras en Europa que trataban sobre los efectos nocivos que causaban estas mujeres en los nińos, fue a mediados del siglo XVIII -cuando la Ilustración desarrollaba sus propuestas evolutivas en estrecha vinculación con la labor médica- el momento culminante de las críticas a esta costumbre y que tuvieron su desarrollo en la práctica fundamentalmente a lo largo del Ochocientos ${ }^{24}$. Se dieron un cúmulo de indicaciones en las que se entremezclaban medidas higiénicas, avances sanitarios y una nueva mentalidad que privilegiaba las relaciones familiares como punto de partida para la felicidad del Estado. Había que delimitar las funciones de cada miembro de la estirpe para que hubiera una correcta armonía entre ellos y no quedara ninguno sin cumplir correctamente su cometido para con el resto.

Unido al reforzamiento del patriarcado, el papel de la mujer se fue definiendo con claridad por temor a las costumbres de algunos sectores en los que el bello sexo había ido adquiriendo mayor relevancia en el ámbito público, desatendiendo con ello las labores inherentes a su género ${ }^{25}$. La labor de la madre fue especialmente atendida por la literatura, eran ellas las que tenían la obligación de permanecer al lado de los hijos menores de edad en todo momento, proporcionándoles, desde su alumbramiento, el alimento, el cariño, el vestuario, la educación básica y las medicinas necesarias.

El alimento más recomendado para que los recién nacidos no tuvieran problemas, ni de salud ni de conducta, era la leche materna ${ }^{26}$, circunstancia que también benefició a los

24 Véase BOLUFER PERUGA, M. «Actitudes y discursos sobre la maternidad en la España del siglo XVIII: la cuestión de la lactancia», Historia Social, no 14, 1992, pp. 3-22 y NOGAL FERNÁNDEZ, R. «Mujer y maternidad: asociación perfecta de la Ilustración» en PÉREZ CANTO, P. y ORTEGA LÓPEZ, M. (Eds.): Las edades de las mujeres, Madrid, Universidad Autónoma, AEIHM, 2002, pp. 291-307. Esta práctica se perpetuó en el tiempo. Los viajeros que llegaban de diversos puntos de Europa a España a menudo hacían referencia a estas mercenarias de la leche. Gautier, por ejemplo, antes de mediar el siglo XIX, hablaba de ellas con cierta admiración: «En el Prado algunas pasiegas de Santander con su traje regional; estas pasiegas son consideradas como las mejores nodrizas de España y el afecto que toman a los niños es proverbial, llevan una falda de paño rojo de grandes pliegues, orillada de un galón ancho, un corpiño de terciopelo negro galoneado también de oro, y a la cabeza un pañuelo de colores, todo ello acompañado de alhajas de plata y otras bravas coqueterías. Estas mujeres son muy guapas y suelen tener un aire de fuerza y de vigor muy chocante». Recogido por MENÉNDEZ PIDAL, G. La España del siglo XIX vista por sus contemporáneos, t. I, Madrid, Centro de Estudios Constitucionales, 1988, pp. 398-399.

BEL BRAVO, M. A. Mujeres españolas en la historia moderna, Madrid, Sílex, 2002, p. 42.

Era lo mejor hasta cierto punto, como indicaron algunos autores. Por ejemplo, Inés Joyes se quejaba de que se tachasen de malas madres a las mujeres que recurrían a las amas de cría, puesto que no todas lo hacían por capricho, sino por lo perjudicada que quedaba su salud tras el parto. También criticaba a los maridos que obligaban a sus esposas a dar de mamar a sus hijos, encontrándose tan débiles. Observando este comportamiento insensible, estas mujeres enfermas físicamente también se hundían anímicamente. La causa fundamental para defenderlas eran los inconvenientes que una leche de mala calidad podía tener para los recién nacidos. JOYES y BLAKE, I. El príncipe de Abisinia. Novela traducida del inglés por Da Inés Joyes y Blake. Va inserta a continuación una Apología de las mugeres en carta original de la traductora a sus hijas, Madrid, Imprenta de Sancha, 1798, pp. 200-201. 
médicos al quitarse la competencia de ciertas comadronas y las amas de cría, extendiendo así su campo de actuación en compenetración con las madres, atentas a sus consejos y remedios ${ }^{27}$. Desprendiéndose de algunas teorías supersticiosas y abogando principalmente por la salubridad, los que siguen eran, en general, los provechos que tanto las madres y los hijos obtenían en la lactancia:

\begin{abstract}
(...) estoy persuadida á que qualquiera muger hace lo mejor en criar por sí misma, quando es robusta, y no la falta leche: lo primero, porque esta es mas provechosa á las criaturas, que la leche de una extrańa: lo segundo, porque la naturaleza próvida tributa á toda madre el alimento que ha de dar á sus tiernos hijuelos; y así solo por accidente las puede ser dañoso, y desmejorarse por criarlos; y á mi parecer es peor violentar la naturaleza con sangrías, y otras medicinas, para que se retire la leche; pues la forzada fuga suele causar algunas enfermedades, como ya ha sucedido: lo tercero, porque mas penoso es sufrir el mal genio, y toscas modales de las amas, que el ligero trabajo de $\operatorname{criar}^{28}$.
\end{abstract}

Los ilustrados sabían que se trataba de una tarea complicada puesto que era una costumbre muy arraigada y extendida a todas las clases sociales, pero también eran conscientes de que parte de esta difusión se debió al ejemplo que durante siglos habían dado los privilegiados. Por tanto, había ahora que dirigir principalmente el discurso a los más favorecidos porque si lograban hacerles entrar en razón, sería cuestión de tiempo que volviera a producirse la imitación. De igual forma, se debían descartar algunas teorías tradicionales y ensalzar otras para aleccionar a las madres.

Durante mucho tiempo y relacionado con la teoría de los humores, se creyó que la leche y la sangre compartían el mismo ámbito y que, por lo tanto, a través de la primera se podían contagiar las enfermedades físicas y los comportamiento desviados e inmorales. Se pensaba que si los infantes lograban sobrevivir tras su etapa con las nodrizas, las condiciones de vida que tendrían en el futuro no serían nada halagüeñas, ni para ellos, ni para la familia y el Estado. La incompatibilidad de la leche de una mujer ajena, de sangre distinta al niño, con frecuencia se decía que producía la intolerancia del recién nacido, al que le acudían diversas enfermedades que arrastraba en su futuro -si lo tenía-, convirtiéndolo en un ser achacoso y débil e impidiéndole trabajar y ayudar en la casa. En definitiva, este tipo de leche podía llegar a transformarlo en una persona gravosa para la sociedad, siendo durante toda su vida un enfermo y no un vasallo útil.

27 También se aconsejaba a las madres que no se excedieran en el tiempo que le daban el pecho a sus hijos: «Luego que los niños se vean constituidos en una regular robustez, deben ser privados del pecho, pues este los afemina, hace pusilanimes, y pone impedimentos á la organización, atonteciendo a los que se detienen mucho tiempo en este alimento». Correo de Murcia, no 272, 7 de abril de 1795, p. 216.

REJÓN Y LUCAS, D. V. op.cit., pp. 10-11. 
Los moralistas advertían a los progenitores del peligro que esta circunstancia de identificación de las dos sustancias podía acarrear al lactante, como, por ejemplo, el hecho de contaminar una sangre de noble linaje con otra de condición baja y servil -pues muchas de las nodrizas eran esclavas o criadas- o de naturaleza conversa o hereje ${ }^{29}$ :

¡Qué lástima, pues, y que locura, fiar al pecho de una vil mercenaria, la nobleza de el alma de un recién nacido, y el vigor de su temperamento, à riesgo de mirar corrompida la una, y debilitando el otro, por una leche estraña, y defectuosa, sobre todo, si la Nutriz fuese Esclava, ó de raza servil, si ha nacido entre barbaros, si sus costumbres son viciosas, su cuerpo mal proporcionado, su conducta libertina, y si es por ultimo apasionada al vino! ${ }^{30}$.

Sin embargo, ciertos pensadores achacaron el problema, no a esta vinculación de fluidos -que empezaba a ser tachada de supersticiosa- sino a la separación de los padres y a la convivencia con estas rústicas e ignorantes mujeres, lo que solía tener consecuencias desastrosas en la educación de los niños. Porque hay que tener en cuenta que aunque ciertas nodrizas vivieran en la casa de los padres del niño, algunas otras se hacían cargo de los infantes en sus propias viviendas. Si lograban sobrevivir, eran devueltos a la familia sobre los tres años de edad, en el mejor de los casos $^{31}$.

A parte de la rusticidad de estas mujeres, la escasa atención que dedicaban a los infantes era otro de los motivos de crítica de la época. Trabajadoras del campo o sirvientas en su mayoría, estas féminas no podían desligarse totalmente de sus obligaciones para atender con exclusividad al lactante. Algunas los llevaban consigo mientras realizaban sus faenas y otras apenas les daban el suficiente sustento, puesto que también debían de alimentar y cuidar a sus hijos. Sin embargo, estudios del tema, como los de Sarasúa para Madrid, advierten que esta circunstancia de convivencia entre los «hermanos de leche» no era nada común. La mayoría contrataba a otra nodriza, a poder ser sin nińos y viuda, o los dejaban en la Inclusa, Casa de Expósitos o Casa de Misericordia ${ }^{32}$. Otras los abandonaban en las calles:

Avisan de Valencia, que el 28 de Diciembre próximo pasado, sacaron de un aqüeducto subterráneo una Niña recién nacida, que según se considera, la conduxo el agua mas de una legua por bajo de tierra; sacaronla viva y sin la menor lesión, por lo que la bautizaron imponiéndole del nombre de Maria Salvadora ${ }^{33}$.

29 GUILLAMÓN ÁLVAREZ, J. Honor y honra en la España del siglo XVIII, Madrid, Universidad Complutense de Madrid, 1981, p. 14.

30 Correo literario de Murcia, t. II, 1792, p. 6.

31 SARASÚA, C. Criados, nodrizas y amos. El servicio doméstico en la formación del mercado de trabajo madrileño, 1758-1868, Madrid, Siglo Veintiuno de España Editores, 1994, p. 154.

32 Ibidem, p. 163.

33 Diario de Murcia, no 3, 3 de enero de 1792, p. 12. 
En las Inclusas las madres dejaban a sus hijos en unos tornos para que las monjas no pudieran conocer su identidad. Los recién nacidos eran bautizados, pasaban a manos de las nodrizas y cuando crecían se les adoctrinaba en colegios, si eran nińos, o se les hacía trabajar cosiendo bolsos, guantes, etc., si eran niñas. En ocasiones, en la prensa se daban noticias sobre el número de expósitos y las condiciones en que se entregaban a las amas de leche:

\begin{abstract}
Desde 10 de Enero de este ańo à 30 de Junio proximo, entraron en la Real Casa Inclusa de esta Ciudad 68 Niños Expositos: quedaron en dicho dia 169: se entregan con el Niño á la Ama, dos embolturas de ropa, se dá una de quatro á quatro meses según la edad: y se pagan 30 reales el último dia de cada mes: si alguna Ama quisiere algun Exposito acuda á dicha Real Casa: si fuere de algun Lugar distante hasta quatro Leguas de esta Ciudad, traerá certificación de su Cura, ó persona de esta que la abone ${ }^{34}$.
\end{abstract}

En estos espacios había una tasa muy elevada de mortalidad infantil, además el número de párvulos que se dejaba en estos centros no hizo sino aumentar con el paso de los años, debido, en muchas ocasiones, a embarazos no deseados o ilegítimos. Aunque el destino de los niños de estas dependencias era incierto, las madres solteras o las prostitutas preferían dejarlos en las Inclusas por su incapacidad de mantenerlos o porque intuían que el futuro que les aguardaba si seguían con ellas no sería nada halagüeño.

Cabarrús criticaba la costumbre de dejar a los niños en estos lugares, pero no atacando a las madres, sino a la sociedad del momento que con las trabas, engańos y escarnios a que sometía a estas mujeres era la máxima responsable en la toma de esta decisión. Estas mujeres no tenían más opciones porque eran «objeto de los placeres, de la corrupción, y del desprecio de nuestras ciudades populosas» y porque casi todas habían sido «seducidas, engañadas, sacrificadas por nuestros perversos sistemas, y arrastradas á una degradación» que era la causa de su tormento. Creía en la importancia de los vínculos entre madre e hijo por lo que buscaba una solución al problema preguntándose:

¿no podrá existir algún medio político de reconciliar con el honor aquella mujer frágil que sólo ofendió al recato? El cumplimiento exacto de las obligaciones de la madre ¿̨no pudiera hacer olvidar el delirio momentáneo de una amante crédula y fácil ${ }^{35}$ ?

Había otras causas para entregar los niños a estas Casas de Expósitos como en el caso de los hijos legítimos cuyos padres no podían mantenerlos y preferían cederlos a

$\overline{34}$ Ibidem, no 66, 5 de julio de 1792, p. 261.

35 CABARRÚS, C. Cartas sobre los obstáculos que la naturaleza, la opinión y las leyes oponen a la felicidad pública, Vitoria, Don Pedro Real, 1808, pp. 44-48. 
esta institución durante un tiempo, hasta que consiguieran posibles ${ }^{36}$. Esta opción puede ser considerada como la más benévola e idealizada. Sin embargo, lo más común era que la entrega de estos hijos dentro del matrimonio se produjera por familias incapaces de hacer frente a los gastos de su manutención, por lo que raras o prácticamente inexistentes serían las veces en las que los padres regresarían por ellos ${ }^{37}$. También, entre la élite, era un recurso para no perder el prestigio social por un embarazo ilegítimo, causa de escándalo, deshonra y pérdida de las hijuelas ${ }^{38}$.

La consideración que se tenía de estos lugares era bastante pésima, pues normalmente no cuidaban las condiciones higiénicas, los niños apenas estaban alimentados y se hacinaban en habitaciones mínimas sin ventilación, donde los contagios de enfermedades formaban parte de la rutina diaria ${ }^{39}$. Destaca al respecto un tratado de principios del siglo XIX donde se apuntaban las causas más frecuentes de mortandad de expósitos en las Inclusas y Hospicios y del modo de subsanarlas. En esta obra se pretendía mejorar la calidad de las nodrizas y la de los sirvientes y facultativos de los centros para que pudiesen solventar con mayor diligencia las enfermedades de los niños, acabar con los problemas de ventilación y limpieza, fomentar la práctica del ejercicio y aportar soluciones para la escasez de los fondos de dichas instituciones. Reflexiones todas ellas amparadas en un deseo notable de conseguir el aumento de la población y la felicidad pública por medio del servicio de un gran número de vasallos que se estaban perdiendo, debido a las malas condiciones de estos centros.

Las malas condiciones en las que se hallaban, provocaban el rechazo de las familias a adoptar a estos niños, a lo que se le unía la falta de una educación adecuada. El párrafo siguiente alude a uno de los problemas que se producían al adoptarlos y cómo se divulgaba con rapidez en la comunidad vecinal:

Como se juntan muchos parbulitos en el Depósito, sin distinción de ropa, cuna y pecho, y con mucha debilidad, contraen una especie de contagio ò sarna, que además de causar en ellos estragos, impide les saquen à criar, porque infestando la que lleva

36 FERRÁNDEZ OBRADORS, V. ob.cit., p. 27.

37 CARO LÓPEZ, C. La línea de sombra. Estudios sobre la asistencia y la represión de los marginados en Murcia durante el siglo XVIII, Murcia, Ayuntamiento de Cartagena, 1992, p. 16.

38 LÓPEZ PICHER, M. «Los primeros ańos de la inclusa de La Coruña, bajo el patronato de la Venerable Congregación del Divino Espíritu Santo y María Santísima de los Dolores (1793-1799)» en CAMPOS y FERNÁNDEZ DE SEVILLA, F. J. La Iglesia española y las instituciones de caridad, Madrid, Ediciones Escurialenses, 2006, pp. 612-613.

39 URIZ, J. X. Causas prácticas de la muerte de los niños expósitos en sus primeros años: remedio en su origen de un tan grave mal: y modo de formarlos utiles a la Religión y al Estado, con notable aumento de la Poblacion, fuerzas, y riqueza de España, Pamplona, Josef de Rada, 1801. En la misma línea, aunque algo más específico -por ejemplo, incluye tablas en las que, según la fase de lactancia de la criatura, detalla los alimentos, las cantidades de éstos y las horas del día en que deben tomarlos-, véase GARCÍA, S. ob.cit. 
alguna à su familia, comunica su desgracia y desacierto en haberse encargado de él à las vecinas, y de éstas se propaga la noticia à todo el Pueblo, que se reserva muy bien aun del pensamiento de criarles ${ }^{40}$.

Carlos III intentó que se superasen estas trabas mandando a los Rectores de estas Casas para que vigilasen con esmero que los expósitos recibían el alimento debido, que se les instruía en materias apropiadas para convertirlos en vasallos útiles y que no se les entregaba a personas de dudosa condición que abusarían de la condición indefensa de los párvulos ${ }^{41}$.

En la documentación notarial hay algún caso de prohijación, donde se muestra la consideración desigual que se tenía de estos niños en comparación con los hijos legítimos ${ }^{42}$. En el ejemplo siguiente la otorgante expresó haberse casado tres veces sin haber tenido descendencia. En su testamento mencionó la prohijación que hizo con su segundo marido de una niña de dos años y a pesar de que éste nombró por heredera a la infanta, revocó tal cláusula, seguramente por designar a su actual esposo y a su ánima como beneficiarios de sus bienes:

Durante el matrimonio con Francisco Bustamante se recibió en prohijación de las Reales Pías fundaciones a una niña exposita de edad de dos años y medio llamada Francisca de Borja, sobre que se otorgó escritura y su contesto no lo entendí, ni me instruí de las obligaciones que se contraen en semejantes casos, si solo oy en el acto del

40 BILBAO, A. Destrucción y conservación de los Expósitos, Málaga, Félix de Casas y Martínez, 1709, p. 14.

41 Novísima Recopilación de las Leyes en España, Libro VII, Título XXXVII, Ley III, Madrid, Imprenta de Sancha, 1805, p. 688; MURCIA, P. J. de. Discurso político sobre la importancia y la necesidad de los Hospicios, Casas de expósitos, y Hospitales, que tienen todos los estados y particularmente España, Madrid, Viuda de Ibarra, 1798, pp. 66-91. Esta obra incluye en sus apéndices la "Carta Real, y Supremo Consejo de Castilla, Circular á todos los Prelados del Reyno, con fecha de 6 de Marzo de 1790, para que se informasen el estado de los Nińos Expósitos, y sus Casas».

42 Había diferentes tipos de escrituras de crianza, lo que implicaba que los adoptantes elegían el grado de compromiso que adquirirían con el expósito. Así, podían incluirlos como herederos, hacerlo en el caso de no tener descendencia o únicamente otorgarles la cantidad necesaria para que tomasen estado. FRESNEDA COLLADO, R. y ELGARRISTA DOMENEQUE, R. «Aproximación al estudio de la identidad familiar: el abandono y la adopción de expósitos en Murcia (1601-1721)» en CHACÓN JIMÉNEZ, F. (Coord.): Familia y sociedad en el Mediterráneo occidental: siglos XV-XIX, Murcia, Universidad de Murcia, 1987, pp. 108-109. Según algunos estudios, la tendencia en la época, a diferencia de lo que ocurre hoy día, era adoptar a los expósitos a partir de los dos años de edad. Principalmente eran los matrimonios los que los solicitaban, pero, conforme avanzó el siglo, aumentaron considerablemente las solicitudes de las mismas nodrizas que los habían criado para hacerse con la prohijación de los infantes, prefiriendo a los varones. TARIFA FERNÁNDEZ, A. "Aproximación a la práctica del prohijamiento en la Casa-Cuna de Úbeda (1665-1788) ¿Los otros hijos?» en RODRÍGUEZ SÁNCHEZ, A. y PENAAFIEL RAMÓN, A. Familia y mentalidades. Seminario Familia y élite de poder en el Reino de Murcia. Siglos XV-XIX, Murcia, Universidad de Murcia, 1997, p. 87. 
otorgamiento de ella que quando esta tomare estado o falleciesemos debía darsele trescientos reales de vellón (...) Pero al fallecer su marido llegó a entender que la escritura tenía la particularidad de que había que nombrarla por sus fallecimientos heredera de los vienes que dejasemos. Pero este punto no lo entendió entonces, para no tener cargo de conciencia lo consultó espiritualmente y no está obligada a dejarla como heredera de sus bienes ${ }^{43}$.

Si bien, no siempre se actuaba de tal modo. Algunas personas pusieron especial empeño en la educación de estos hijos que adoptaban y del futuro que les aguardaba, al igual que lo habían hecho con sus propios descendientes:

(...) a Isabel Manzano, que estoy criando en las casas de mi morada le suplico a Don Francisco Soler mi hijo le acave de criar a sus costumbres poniéndole presente el santo temor de Dios, preceptos que debe guardar y cumplir de nuestra Santa Madre Iglesia y si llegase a tomar estado, quiero y es mi voluntad le de y entregue setecientos cinquenta reales de vellón su cama, y tablado con dos colchones poblados de lana, dos cabeceras, quatro sábanas y la ropa de su uso ${ }^{44}$.

La actuación de la Junta de Damas de Honor y Mérito de la Matritense fue decisiva para sentar los precedentes en la adecuación sanitaria e higiénica de este tipo de instituciones. Tras observar la elevadísima tasa de mortalidad que había en la Real Inclusa de Madrid, solicitaron en varias ocasiones al rey el permiso para hacerse cargo de la misma. Pasaron algunos años hasta que Carlos IV les permitió realizar un informe sobre la situación real del centro, otorgándoles poderes en 1797. A pesar de que dicha investigación estuvo plagada de trabas e inconvenientes por parte de los administradores y empleados, el informe presentado fue tan demoledor que lograron la venia del monarca para dirigir la Inclusa en 1799. A partir de entonces se sucedieron las obras de limpieza, desinfecciones periódicas, ventilación de las salas e inspección médica de infantes y amas de cría. Según relató Fernández-Quintanilla, de una tasa de mortalidad del 96 por ciento en 1799, se llegó a un 36 por ciento en $1803^{45}$.

Carlos IV quiso también favorecer la situación de estos hijos ilegítimos, o de padres no conocidos, decretando su legitimidad en todos los efectos civiles, integrándolos en la clase social de hombres buenos del estado llano, acabando con el

43 Archivo Histórico Provincial de Murcia [AHPMU], Sección Protocolos Notariales, Signatura 2580, 1793, ff. 190r.-191r., (Murcia, 2-X-1793).

44 Ibidem, Signatura 6037, 1769, ff. 142v. -143r., (Cartagena, 24-I-1769).

45 FERNÁNDEZ-QUINTANILLA, P. La mujer ilustrada en la España del siglo XVIII, Madrid, Ministerio de Cultura, 1981, pp. 93-95. Véase DEMERSON, P. de. «La Real Inclusa de Madrid a finales del Siglo XVIII», Anales del Instituto de Estudios Madrileños, no VIII, 1972, pp. 261-272. 
veto de ocupación de ciertos oficios y permitiendo que pudieran acudir a colegios de huérfanos o disfrutar de las dotes para casamientos de doncellas pobres ${ }^{46}$.

\title{
4. EL VESTUARIO Y LOS CUIDADOS FÍSICOS
}

Otros consejos se ofrecían a las madres de la época para que salvaguardaran la salud de sus retoños ${ }^{47}$. Tradicionalmente se creía que ciertas papillas y brebajes daban fuerza a los recién nacidos para afrontar los primeros días de vida, además, se les fajaba, es decir, se envolvían sus diminutos cuerpos con numerosas vendas que impedían su movimiento en la creencia de que así se formarían mejor físicamente. El fajado recibió especial atención en tanto que, aparte de propiciar un crecimiento deforme de las partes del cuerpo y producirles casi la asfixia, era un recurso muy común que usaban algunas madres -sobre todo las campesinas- para dejar solo al nińo, sin poder moverse, y continuar con sus labores:

\begin{abstract}
(...) luego que sale al mundo tiene encima tantos lios y envolturas, como si le hubiesen roto todos los huesos al nacer; y como estos son tan delicados, no solo comprimen y lastiman la tierna máquina, sino que dificultan el movimiento del corazón, de los pulmones y demás órganos necesarios para la vida ${ }^{48}$.
\end{abstract}

Estas conductas eran tachadas por los ilustrados como egoístas, desaprensivas y crueles, propias de mujeres indignas de tener hijos. Su principal función era darse a sus retoños, ocupando su tiempo en sus cuidados y poniendo toda su atención en que ninguna enfermedad los atacara. Se aconsejaba, por tanto, que los recién nacidos no se envolvieran en prendas apretadas que pudieran impedir la respiración y la circulación de la sangre. $\mathrm{Al}$ contrario, debía ponérsele «ropa para estar abrigados y que esta sea desembarazada ${ }^{49}$ »,

46 Novísima Recopilación... ob.cit., Libro VII, Título XXXVII, Ley IV, pp. 688-689. En aquella sociedad se tildaba a los expósitos de ser unos «bastardos, espúreos, incestuosos o adulterinos». En la citada ley se recordaba que muchos eran los hijos legítimos de matrimonios que habían sido puestos por sus padres en hospicios o casas de recogida ante la escasez de medios de éstos para poderlos atender. CORTÉS CORTÉS, F. «Atenciones a expósitos en la Extremadura del siglo XVIII», Studia Histórica. Historia Moderna, no 12, 1994, p. 149.

47 Sobre la literatura médica-higienista infantil en la España de la Ilustración véase ROBLES SEGUI, A. «El niño y la literatura pediátrico-educativa en la España Ilustrada» en Educación e Ilustración en España, V. III, Barcelona, Universidad de Barcelona, 1984, pp. 543-553. También resultan interesantes las referencias sobre las obras relevantes que se redactaron a nivel europeo sobre medicina y educación, desde finales del siglo XVIII a mediados del siglo XX, que recoge VINÁ FRAGO, A. «Higiene, salud y educación en su perspectiva histórica», Areas, n 20, 2000, pp. 9-24.

48 BUCHAN, G. Medicina doméstica, ó tratado completo del método de precaver y curar las enfermedades con el régimen y medicinas simples y un apéndice que contiene la farmacopea necesaria para el uso de un particular, Madrid, Ramón Ruiz, 1792, p. 10.

Ibidem, p. 14. 
realizadas con telas finas en verano y de algodón o franela en invierno, un casquete o gorro para protegerle la cabeza, atado por la barbilla, «un metedor que reciba los excrementos y la orina y sujetando todo con un ceñidor alrededor del cuerpo ${ }^{50}$ ». Así se dejaban las piernas y las manos libres. Al cumplir los primeros años, es decir, cuando empezaran a vestir de corto hasta que lo hicieran como los adultos (desde el destete hasta los cinco años más o menos), los tratados sobre la crianza física infantil exhortaban a los padres para que acabaran con la costumbre perniciosa de colocarles cotillas. Este artefacto causaba a los niños problemas respiratorios, circulatorios y digestivos que los hacía fallecer a una edad temprana ${ }^{51}$.

En los inventarios y testamentos analizados de Murcia y Cartagena las fajas de niño denominadas como tal apenas son frecuentes. La ropa de niño, fundamentalmente de los recién nacidos, no es muy prolija, hay poca variedad de documentos en los que se especifique alguna prenda infantil y sólo se ha hallado un legajo en el que se inventaría la «ropa de niño» como un epígrafe separado y distinguido de los demás. Este apartado incluía: tres mantillas de niño; tres mudados de niño; saco de cotonia; delantal y enaguas de trué; mantilla de cotón con clarín y pañal de trué de lienzo alemanisco; delantal de clarín con trapo de leche ${ }^{52}$. Esta última denominación podría referirse a que el delantal incorporaba una especie de babador para el recién nacido.

Aparecen en primer lugar varias referencias a las piezas para bautizar -sólo en dos ocasiones se menciona que son de «cristianar» o «acristianar ${ }^{53}$ »- como mantillas («mantilla de cotonia blanca con fleque para bautizar ${ }^{54}$ ), «enanguetas» o «senanguetas», delantales, carotas, pañuelos, paños y, como denominación genérica, «ropa de bautizar», sin especificar más. No podemos asegurar a qué prendas hace alusión el término «enanguetas» o «senanguetas», ya que no está reflejado en ningún diccionario de la época. Sin embargo, se cree que puede tratarse de unas enaguas pequeñas. En inventarios de otras zonas de España como Madrid se hacía referencia a enaguas de niño. Entre los bienes que quedaron tras el fallecimiento de María Ignacia Álvarez de Toledo Gonzaga y Caraciolo, hija del X Marqués de Villafranca del Bierzo y esposa del Duque de Maqueda y Gobernador

50 GINESTA, A. El conservador de los niños, Madrid, Imprenta Real, 1797, pp. 6-7.

51 BALLEXERD, N. Crianza física de los niños desde su nacimiento hasta la pubertad, y método el mas seguro de robustecer la Especie humana contra los insultos de las enfermedades, Madrid, Antonio Espinosa, 1787, pp. 92- 93.

52 AHPMU, Sección Protocolos Notariales, Signatura 2616, 1795, sin foliar [s./f.], (Murcia, 21VIII-1795).

53 En la zona de La Bañeza el traje de acristianar estaba formado por una mantilla que envolvía al niño, sobre los pañales, sujetada con un orillo de varios colores. Sobre la mantilla se ponía una galona - pequeña toca de tres picos con puntilla- y un gorro con numerosos bordados, sobrepuestos de fieltro y varias cintas de colores. CAVERO, O. y ALONSO, J. Indumentaria y joyería tradicional de La Bañeza y su comarca, León, Instituto leonés de Cultura, 2002, pp. 39-40.

54 AHPMU, Sección Protocolos Notariales, Signatura 5672, 1772, ff. 299v., (Cartagena, 15-XII1772). 
del Banco de San Carlos Vicente Joaquín Osorio de Moscoso, se mencionaron: «veinte y dos pares de enaguitas sin mojar» en doscientos veinte reales, «veinte y cinco pañales de cotanza sin mojar» en trescientos cincuenta reales, «veinte y seis metedores de lo mismo» en ciento cuatro reales y "catorce pañales de nesga sin mojar» en ciento doce reales de vellón ${ }^{55}$.

Las carotas - palabra que tampoco aparece recogida en el Tesoro de la Lengua de Covarrubias, en el Diccionario de Autoridades o en el Diccionario de Terreros y Pandoprobablemente eran los gorritos ${ }^{56}$ a los que hacía alusión anteriormente Ginesta, ya que suelen aparecer junto al resto de piezas indumentarias que configuraban la totalidad del vestuario del recién nacido, es decir, junto a fajas o «cruzadores», pañales, capotes, mantillas o delantales, y en la mayoría de los casos presentan encajes o bordados. Las mantillas ( «tres mantillas de envolver ${ }^{57}$ ), los pañales y las fajas entran dentro de las prendas consideradas en la época como envolturas del niño ${ }^{58}$. En referencia a la Santísima Trinidad era costumbre colocar tres mantillas al recién nacido. La de arriba solía ser encarnada, la de en medio verdosa o amarilla y la de abajo o en contacto con la piel blanca. Por el mismo motivo se les ponían tres gorros ${ }^{59}$.

El pañal en este momento era una sabanilla de lienzo o tela con que se cubría y rodeaba al niño. Las ropas que actuarían como los pañales que entendemos en la actualidad eran los mudados, metedores o bragas ${ }^{60}$ («tres pañales y dos bragas de lino usados $\left.{ }^{61} »\right)$, principalmente realizados en lienzo o lino.

En un documento de Cartagena con los bienes que quedaron por la muerte de Magdalena Ruiz se inventarió «ropa de criatura, diferentes camisicas y coleticos ${ }^{62}$ ». También se ha hallado un vaquero, una prenda suelta, larga y fácil de llevar que en siglos anteriores habían utilizado las mujeres para cazar o pasear y que también usaron los infantes de ambos

55 Archivo Histórico de Protocolos de Madrid [AHPM], Sección Protocolos Notariales, Signatura 22255, 1796, ff. 794r., (Madrid, 23-II-1796).

56 Este gorrito tenía diversas denominaciones según la zona: «Se les debe poner en la cabeza un frontero, ó chichonero, como llaman en algunas partes de Castilla, que sobresalga por delante mas que la nariz, para que si caen les liberte la cara lo mas que se pueda». BALLEXERD, N. ob.cit., pp. 83-84.

57 AHPMU, Sección Protocolos Notariales, Signatura 2938, 1763, ff. 86v., (Murcia, 2-V. 1763).

58 RISCO, A. «Mantener una casa en Madrid: modelos familiares y economía doméstica hacia 1766» en SOUBERYROUX, J. y FERNÁNDEZ, R. (Coords.): Historia social y literatura: familia y clases populares en España (siglos XVIII-XIX), Lleida, Milenio, 2001, p. 46.

59 Agradezco este dado al Dr. D. Antonio Cea Gutiérrez, Investigador Científico del CSIC.

60 La denominación metedor y braga no es usual en la zona murciana. Lo más común era el término mudado que también se aplicaba a la ropa interior blanca de los adultos.

61 AHPMU, Sección Protocolos Notariales, Signatura 4735, 1808, ff. 280r.-306v., (Murcia, 25-V1808).

62 Ibidem, Signatura 6034, 1763, ff. 337r., (Cartagena, sin fechar). 
de sexos: «vaquerillo de rasoliso forrado en lienzo de la niña más pequeña ${ }^{63}{ }$. Algunos modelos de este atavío infantil tenían la particularidad de que incorporaban mangas tubulares para sujetarlos cuando aprendían a andar ${ }^{64}$.

Cabe añadir que fue a finales del siglo XVIII cuando los niños comenzaron a vestirse de manera diferente a los adultos, una vez que empezaban a andar. Incluso se convirtieron, como puntualizó Pérez Monroy, en «vanguardia de la moda», pues fueron los primeros que de manera constante hicieron uso del pantalón largo ${ }^{65}$. Entre las clases altas, la indumentaria que tanto niños como niñas empezaron a usar en esta época se caracterizaba por la sencillez y la comodidad, propiciada por el auge en la utilización del lino y el algodón ${ }^{66}$. Diseńos y tejidos que favorecían la movilidad, el juego y el descanso.

Además de estas críticas sobre el vestuario, los higienistas y médicos europeos también denostaron, entre otras, la costumbre de que las madres durmieran en la misma cama que los pequeños ${ }^{67}$, la de dejar a los niños solos o a cargo de hermanos mayores, ponerlos en andadores o la manera de cogerlos con movimiento bruscos, sin tener en cuenta lo delicado de sus órganos.

También se dieron recomendaciones sobre el tipo de alimentación que más les convenía una vez hubieran sido destetados ${ }^{68}$, el tipo de juegos más apropiados, la importancia del ejercicio, etc. Además, una vez comenzaran a tener discernimiento, se instaba a los padres y familiares de los chiquillos a que evitaran cualquier "motivo de susto", como las historias de brujas, voces deformadas, ruidos inesperados u objetos que les causasen pánico. El miedo les provocaba enfermedades según refería Ballexerd:

63 Ibidem, Signatura 4045, 1769, s./f., (Murcia, 24-X-1769).

64 ALBALADEJO MARTÍNEZ, M. Apariencia y representación de las infantas Isabel Clara Eugenia y Catalina Micaela en la corte de Felipe II, Tesis doctoral, Murcia, Universidad de Murcia, 2011, p. 176.

65 PÉREZ MONROY, A. J. «Modernidad y modas en la ciudad de México: de la basquiña al túnico, del calzón al pantalón» en STAPLES, A. (Coord.): Historia de la vida cotidiana en México. Bienes y vivencias. El siglo XIX, t. IV, México, El Colegio de México, Fondo de Cultura Económica, 2005, p. 76.

66 Véase GARCÍA FERNÁNDEZ, M. «Entre paños y algodones: petimetres y castizas. ¿"La nueva moda en el arca se vende"?» en GARCÍA HURTADO, M. R. La vida cotidiana en la España del siglo XVIII, Madrid, Sílex, 2009, pp. 125-153.

67 Algunos bebés, tras dormir con sus madres, amanecían muertos y amoratados. Aunque los médicos denunciaban que eran las propias madres las que los asfixiaban echando sus cuerpos sobre las criaturas en sueños, la superstición reinante entre la plebe lo achacaba a las fuerzas maléficas y demoníacas. Por ejemplo, en Canarias, se decía que eran las brujas quienes se colaban en las alcobas y les chupaban la sangre mientras dormían. HERNÁNDEZ GONZÁLEZ, M. ob.cit., pp. 41-42.

68 En el periodo que transcurría entre el destete y la edad de cinco años, se descartaban: «(...) alimentos salados, picantes ó llenos de especias, el comerlos demasiado calientes, los licores y las confituras ó cosas dulces». BALLEXERD, N. ob.cit., p. 133. 
(...) pues fixándoseles qualquiera de ellas en la imaginación, les produce sueños temerosos, y por conseqüencia violentas emociones en los nervios, que les ocasionan alferecía, á la qual por sí mismos están sobradamente dispuestos ${ }^{69}$.

Las enfermedades propias de su edad, como el mal desarrollo psicomotriz o los problemas derivados de la dentición, también tuvieron protagonismo ${ }^{70}$. Sin embargo, en esta época, todavía no se publicaron en España obras dedicadas con exclusividad a las patologías infantiles, fundamentalmente eran artículos presentados a las sociedades médicas o capítulos de amplios tratados en los que también se discernía sobre el estado de los hospicios, los deberes de las madres o las epidemias.

En la España dieciochesca, para paliar determinados padecimientos físicos en los primeros ańos de edad, siguieron utilizándose diversos talismanes y amuletos en los que se entremezclaba lo religioso con lo profano, mágico y supersticioso. Objetos que se colocaban en la cintura, cosidos a las prendas y colgados de los babadores de los recién nacidos ${ }^{71}$. La intención primordial que tenía el uso de estas piezas estribaba en la creencia de que con ellos podían combatirse las fuerzas malignas de los espíritus y de las brujas, las enfermedades, el mal de ojo o la fascinación, el alunamiento y otros influjos naturales, así como favorecer o mejorar diversas funciones físicas como el flujo de la sangre, la dentición o la lactancia. Principalmente se trató de proteger a los niños durante los primeros años de su vida, etapa por antonomasia de indefensión, con un alto grado de mortandad en épocas pasadas.

A lo largo del siglo XVIII en diversas ciudades españolas siguió fuertemente arraigada la antigua creencia en el mal de ojo, a juzgar por el tipo de amuletos que los individuos tenían entre sus posesiones. Esta especie de hechizo, también conocido como aojamiento o fascinación, se producía a través de la mirada de determinadas personas, voluntaria o involuntariamente. En el primer caso se asociaba a las brujas o hechiceros, individuos que conocían las artes oscuras y sabían cómo producir el aojo. En el segundo caso, los malhechores eran personas que no eran conscientes de esta facultad pero que aun así lograban causar este mal mediante sentimientos exacerbados de envidia, odio e

69 Ibidem, pp. 120-121.

70 A principios del siglo XIX, Bustos, cirujano dentista de la Corte, publicó una obra sobre la dentición donde, aunque no trataba en exclusiva de los niños, incluyó alguna mención sobre los cuidados de la dentadura infantil o los dientes de leche: «Es demasiado común la imprudencia de meterse á arrancar los dientes y muelas con hilos, cuerdas y otros artificios, causando con estas maniobras daños irreparable que no pueden conocer los que carecen del arte». BUSTOS Y ANGULO, V. El conservador de la dentadura y de los niños en la dentición, Madrid, Imprenta de Villalpando, 1807, p. 26.

71 Véase BLANCO, J. F. «Magia y simbolismo en la indumentaria tradicional» en Moda en sombras, Catálogo de la exposición, Madrid, Ministerio de Cultura, 1991, pp. 40-47. 
incluso amor ${ }^{72}$. Los trastornos que la fascinación producía en sus víctimas no se asociaban a ninguna enfermedad conocida en concreto, puesto que afectan a diversas partes del cuerpo. Lo más común es que sufrieran fuertes dolor de cabeza, angustia, trastorno en el pulso, falta de apetito, estreńimiento y ojos caídos ${ }^{73}$. Para evitar este mal se utilizaron diversos amuletos, algunos de los cuales venían usándose desde la Antigüedad. Estos dijes debían llevarse siempre a la vista para captar la atención del aojador y que no pudiera evitar fijar su mirada en ellos antes de hacerlo en la posible víctima. La capacidad de estos amuletos de absorber el interés de los poseedores de esta maléfica cualidad, hacía que la misma se descargara sobre ellos, resultando ilesos los portadores ${ }^{74}$.

Uno de los amuletos más antiguos contra el mal de ojo fue la higa. Se trata de un objeto defensivo de origen pagano que simbolizaba la unión del órgano genital masculino con el femenino y que llegó a España a través del comercio con los fenicios y los griegos $^{75}$. Esta mano invertida con el pulgar entre el índice y el corazón fue ampliamente difundida por los musulmanes, gozando de gran popularidad a partir de los siglos XVI y XVII como elemento apotropaico y profiláctico. Aunque se cristianizó incorporándole medias lunas, veneras en alusión al Apóstol Santiago o rosas de Jericó, su uso era considerado supersticioso por ciertos círculos que no podían concebir el hecho de que estuviera tan extendida la utilización de un elemento pagano y con tintes obscenos. En 1633 el jesuita Nieremberg decía al respecto:

De los remedios del aojo no me toca tratar, algunos son supersticiosos. El de la higa que traen los niños, es indigno que le usen los Christianos, y no dudo, sino que se supiese su principio, se dexará totalmente. Es su origen tan de supersticiosos, è idolatras, y por otra parte tan suzio, y abominable, que ni aun pensarla pueden un pecho Religioso, quanto menos dezirla, si bien el azabache, no dexa de ser provechoso, la efigie solo condeno ${ }^{76}$.

Especial raigambre tuvieron las higas de azabache, en tanto que se trató de un material al que se asociaban varias virtudes protectoras y curativas. También se le añadió la vertiente devocional por su relación con el santo compostelano, lugar donde existía

72 HERNÁNDEZ BERMEJO, M. A. y SANTILLANA PÉREZ, M. «La hechicería en el siglo XVIII. El Tribunal de Llerena", Norba, no 16, 1996-2003, pp. 406.

73 ZAPATA GOLLÁN, A. Supersticiones y amuletos, Santa Fe, Ministerio de Educación y Cultura, 1977 , p. 40.

74 FRAILE GIL, J. M. Disquisiciones galanas. Reflexiones sobre el porte tradicional, Salamanca, Centro de Cultura de la Diputación de Salamanca, 2002, p. 151.

75 LABEAGA MENDIOLA, J. C. "Amuletos antiguos contra el mal de ojo en Viana (Navarra)», Zainak, no 8, 1991, pp. 51-52.

76 NIEREMBERG, J. E. Oculta filosofía de la sympatia y antipatía de las cosas, artifico de la naturaleza, y noticia natural del mundo y segunda parte de la Curiosa Filosofia, Madrid, Imprenta del Reino, 1633, p. 42. 
una floreciente industria del azabache. Desde tiempos remotos el azabache fue utilizado también contra el aojamiento. De esta forma, las higas realizadas en este material se creía veían reforzados sus poderes protectores. La materia servía de defensa o preservación contra la fuerza maligna y la forma combatía de manera más activa y ofensiva el hechizo una vez lanzado por el aojador ${ }^{77}$.

Existían otro tipo de amuletos para combatir el mal de ojo, como la mano de tejón, la sirena o el león, los cuernos o la caracola. Asimismo, campanillas, castańas de Indias y sonajeros fueron habituales como objetos defensores del aojamiento, aunque también se les asociaban otros poderes y funciones.

La mano o garra de tejón, también denominada «mano de Fátima ${ }^{78}$ » 0 "pezuña de la gran bestia» se estimaba un potente amuleto defensivo y ofensivo para contener el mal de ojo. Su poder residía en las cinco uñas y el pelaje. Las primeras rasgaban y rompían el maleficio, mientras que el segundo distraía a las brujas o aojadores que se veían misteriosamente tentados a contar el número de los pelos ${ }^{79}$. Estas garras siempre aparecen engarzadas en plata y suelen inventariarse junto a otros dijes o amuletos de nińo como las campanillas, los cuernos o las caracolas: «caracola y mano de tejón engarzada en plata con cadenillas de lo mismo para la niña del pecho en veinte reales de vellón ${ }^{80}$.

Otro amuleto muy habitual contra el mal de ojo, utilizado por nińos y mujeres, era la sirena. Objeto que también repelía los malos espíritus y el mal de aire al llevar colgando varios cascabeles ( «sirena de plata con cascabeles en diez y ocho reales ${ }^{81} »$ ) y, en ocasiones, un silbato sobre la cabeza con su correspondiente caja de resonancia, aunque a veces iba independiente: «sirena, corneta y caracol con su castańa en ciento diez y ocho reales ${ }^{82}$ ». El modelo más común presentaba a la sirena en actitud coqueta mirándose en un espejo de mano, mientras en la otra sostenía un peine. Su poder estribaba en su

77 Catálogo de Azabaches compostelanos: precedido de apuntes sobre los amuletos contra el aojo, las imágenes del apóstol-romero y la cofradia de los azabacheros de Santiago, Madrid, s. /e., 1916, p. 12.

78 Los cristianos llamaron «mano de Fátima» a un amuleto musulmán en forma de mano con los cinco dedos extendidos que simbolizaba las cinco reglas esenciales del Corán y que también representaba esquemáticamente la cabeza y las cuatro extremidades del cuerpo humano. FRAILE GIL, J. M. ob.cit., pp. 153-154. Aunque de manera aislada en la documentación, también se hallan este tipo de ejemplares: «mano de cristal engarzada en plata». AHPMU, Sección Protocolos Notariales, Signatura 2818, 1762, ff. 419r., (Murcia, 17-IV-1762). El poder de este amuleto se reforzaba con el material en el que estaba realizado, ya que el cristal de roca se usaba también contra el mal de ojo. ALARCÓN ROMÁN, C. Catálogo de amuletos del Museo del Pueblo Español, Madrid, Ministerio de Cultura, 1982, p. 24.

79 FRAILE GIL, J. M. «Noticias sobre amuletos en Madrid y su entorno», Revista de Folklore, no 353, 2011, p. 10.

80 AHPMU, Sección Protocolos Notariales, Signatura 4045, 1769, s./f., (Murcia, 24-X-1769).

81 Ibidem, Signatura 3797, 1768, ff. 187v., (Murcia, 27-VII-1768).

82 Ibidem, Signatura 3389, 1775, ff. 252 r., (Murcia, 31-XII-1775). 
capacidad, de origen mitológico, de fascinar y embrujar a los hombres. Por medio de su espejo la sirena revertía el mal de ojo, volviéndolo contra el enemigo. Los leones tenían la misma función que las sirenas, los cuales también llevaban cascabeles y silbatos. Además de proteger al niño del aojamiento o de otro tipo de padecimientos, se creía que favorecían el desarrollo físico del infante, aportándoles fortaleza.

Estos enseres también servían para estimular los oídos de los niños, tenerlos localizados y entretenerlos, por lo que en la documentación también se les denominaba «niñerías», "chucherías», «menudencias» o «juguetes»: «dijes y juguetes de niño de plata» en ciento cuarenta reales de vellón ${ }^{83}$. Idéntica función tenían las campanillas o esquilitas que colgaban de los dijeros infantiles: «Dos campanillas de plata, para niños y una medalla del Pilar» en ciento cincuenta reales de vellón ${ }^{84}$. Objetos que en determinadas zonas como Salamanca eran llevados también por las mujeres en las brazaleras para ahuyentar los malos espíritus y evitar el mal de ojo ${ }^{85}$.

Dentro de este tipo de amuletos que se engloban a la vez dentro de las joyas-utensilio se encuentran los chupadores, usados para favorecer la dentición de los recién nacidos, así como para combatir el aojamiento. Este poder residía en este caso en el material y los colores con los que se realizaban. Según refirió Alarcón, eran habituales los chupadores de vidrio transparente recorridos por espirales de tonalidades vivas como el rojo o el azul que lograban atraer la atención de los aojadores, salvaguardando con ello al infante ${ }^{86}$.

Otro tipo de amuletos y talismanes con que se recubría a los niños -aunque alguno de ellos también lo utilizaban los adultos para combatir enfermedades- eran las castañas de Indias, los recipientes olorosos, los evangelios, los relicarios y las cruces. A los dos primeros se le asociaban cualidades para evitar y paliar el mal de aire, causante de enfermedades físicas que determinados objetos, animales o vapores emanaban, penetrando en el cuerpo a través de la boca, oídos o nariz ${ }^{87}$. Una afección corriente entre los infantes que se consideraba causada por el mal de aire era el usagre, erupción cutánea que afectaba principalmente a las orejas y la cara mientras duraba el proceso de dentición. Para combatir este padecimiento era habitual el uso de las castañas de Indias, las cuales también actuaban contra las hemorroides, la gota, la erisipela o el reumatismo.

83 Ibidem, Signatura 3151, 1792, ff. 386r., (Murcia, 18-IX-1792).

84 AHPM, Sección Protocolos Notariales, Signatura, 20386, 1798, f. 822v. (Madrid, 25-IX-1798).

85 CEA GUTIÉRREZ, A. «Supuestos generales para el estudio de la indumentaria» en Es vestir antic. II Jornadas de cultura popular de les Pitiüses, Ibiza, Federació de Colles de Ball i Cultura Popular d'Eivissa i Formentera, 2003, p. 21.

86 ALARCÓN ROMÁN, C. ob. cit., p. 30.

87 RÍOS LLORET, R. E. y VILAPLANA SANCHÍS, S. «Las joyas como ofrenda y protección» en MULLER, P. et. al. La cultura ceñida. Las joyas en la pintura valenciana, siglos XV al XVIII, Catálogo de la exposición, Valencia, Comunidad Valenciana, 2000, p. 57. 
Por su parte, los evangelios protegían a los niños de la fiebre y los alejaban del demonio. Se trataba de unas pequeńas bolsas bordadas con hilos de seda o plata y lentejuelas que acostumbraban a realizar las monjas y que solían albergar fragmentos de los cuatro Evangelios, fundamentalmente del Evangelio de San Juan. Como indicó Fraile Gil, este objeto reunía la cualidad protectora-devocional de la letra impresa con el enigma de lo oculto, pues era costumbre no descoserlos una vez cerrados ${ }^{88}$. Suelen inventariarse junto a amuletos infantiles: "campana de plata y una cruz de lo mismo para niño», "cadena de plata sobredorada» $\mathrm{y}$ «evangelios bordados ${ }^{89}$ ».

Aunque a veces aparecen documentados de manera independiente, por lo común, estos amuletos comentados formaban parte de un dijero, pretinilla o ceñidor que se colocaba alrededor de la cintura de los nińos. En los inventarios de bienes suelen especificarse los amuletos que pendían de los pretinillas: «pretinilla compuesta de un bolsillo de cruces de plata grandes, una sirena, castaña, mano de tejón y caracola con cascabeles todo de plata» en ciento cincuenta y cuatro reales ${ }^{90}$, aunque no siempre. Por ejemplo, Nicolasa Có Llanos dejó a su hija María del Carmen «la ropa necesaria para vestir un nińo con unos dijes de plata ${ }^{91}$ ".

\section{CONCLUSIONES}

De la información que se desprende de la documentación notarial, la literatura, los libros espirituales y la prensa periódica, se advierte que en el siglo XVIII se produjo una realidad de costumbres y corrientes de pensamiento encontradas en lo referente a la manera de atender a los infantes durante los primeros ańos de vida. Los presupuestos y las creencias tradicionales, en los que la religiosidad mantenía un férreo dominio sobre los asuntos corporales, hubieron de convivir en esta época con los avances higiénico-sanitarios que proclamaba la ideología moderna.

Uno de los objetivos de la Ilustración fue mejorar la crianza de los niños con objeto de que pudieran llegar a convertirse en sujetos útiles para el Estado. Una labor que había que iniciar desde la más tierna infancia, cuidando de que los infantes recibieran más atenciones que en etapas pasadas, mejorando su alimentación y aseo y vistiéndolos con prendas que no trabasen su desarrollo psicomotriz. No obstante, pese a las nuevas recomendaciones, siguieron manteniéndose antiguas costumbres como la tendencia de recurrir a las amas de cría o la de fajar a los recién nacidos. Aspecto revelador de una de

\footnotetext{
$88 \quad$ FRAILE GIL, J. M. «Noticias sobre amuletos... ob.cit., p. 18.

89 AHPMU, Sección Protocolos Notariales, Signatura 4718, 1801, ff. 752r.-780v., (Murcia, 10-X1801).

90 Ibidem, Signatura 4044, 1768, ff. 378v., (Murcia, 10-VIII-1768).

91 Ibidem, Signatura, 3738, 1792, ff. 176r., (Murcia, 27-IV-1792).
} 
las características más destacables de la España dieciochesca, la convivencia, difícil en ocasiones, de lo tradicional y lo moderno. 